\title{
Component residual stress control in forward rod extrusion by material flow and tribology-experiments and modeling
}

\author{
A. Jobst ${ }^{1} \cdot$ D. Floros ${ }^{2}$ (D) P. Steinmann ${ }^{2} \cdot$ M. Merklein ${ }^{1}$ \\ Received: 17 January 2021 / Accepted: 21 June 2021 / Published online: 14 July 2021 \\ (c) The Author(s) 2021
}

\begin{abstract}
The forward rod extrusion of ferritic stainless steel X6Cr17 (DIN 1.4016) is here investigated with the objectives to experimentally identify and numerically verify the effect of the lubrication system and die opening angle on residual stresses. Three lubricants $-\mathrm{MoS}_{2}$, soap and polymer - are considered whose tribological properties are characterized via double cup extrusion tests. The effect of material flow is also studied by forming in conical dies featuring three different opening angles. The extrusion experiments revealed a decrease in the near-surface tensile stresses with decreasing friction for all the considered opening angles. An opening angle of $2 \alpha=90^{\circ}$ led to the highest tensile residual stresses. Both an increase to $2 \alpha=120^{\circ}$ and a decrease to $60^{\circ}$ resulted in reduced tensile stresses and even a shift to compressive stresses. Furthermore, a previously developed numerical model of forward rod extrusion is optimized and validated against the experimentally measured residual stresses. The effect of the spatial and temporal discretizations of the model on the predicted residual stresses is investigated. Based on the experimental and numerically verified results, the recommendation to reduce friction in forward rod extrusion is derived as a means to obtain a less detrimental to the lifecycle of extruded parts residual stress state.
\end{abstract}

\section{Steuerung der Bauteileigenspannungen beim Voll-Vorwärts-Fließpressen durch Stofffluss und Tribologie - Experiment und Modellierung}

\section{Zusammenfassung}

In diesem Beitrag wird das Ziel verfolgt, an einem Voll-Vorwärts-Fließpress-Prozess die Einflüsse des verwendeten Schmiersystems und des Stoffflusses auf die Eigenspannungen experimentell zu identifizieren und numerisch abzubilden. In den Untersuchungen werden drei Schmierstoffe $-\mathrm{MoS}_{2}$, Seife und Polymer - verwendet, deren tribologische Eigenschaften im Double-Cup-Extrusion-Versuch ermittelt werden. Der Stoffflusseinfluss wird durch die Verwendung von drei Matrizenöffnungswinkeln untersucht.

Die Umformversuche zeigten abnehmende oberflächennahe Zugeigenspannungen mit abnehmender Reibung für alle untersuchten Schulteröffnungswinkel. Ein Schulteröffnungswinkel von $2 \alpha=90^{\circ}$ führte zu den höchsten Zugeigenspannungen. Sowohl eine Erhöhung auf $120^{\circ}$ als auch eine Reduktion auf $60^{\circ}$ resultierten in verringerten Zug- oder sogar geringen Druchspannungen. Darüber hinaus wurde ein zuvor entwickeltes numerisches Vorwärtsfließpressmodell optimiert und anhand der experimentell ermittelten Eigenspannungen validiert. Der Einfluss der räumlichen und zeitlichen Diskretisierung des Modells auf die vorhergesagten Eigenspannungen wurde untersucht. Auf Basis der experimentell erarbeiteten und numerisch verifizierten Erkenntnisse wurde die Empfehlung abgeleitet, die auftretende Reibung zu verringern, um den Eigenspannungszustand fließgepresster Bauteile zu verbessern.

A. Jobst

andreas.aj.jobst@fau.de

D. Floros

dimosthenis.floros@fau.de
1 Lehrstuhl für Fertigungstechnologie, FAU Erlangen-Nürnberg, Egerlandstraße 13, 91058 Erlangen, Germany

2 Lehrstuhl für Technische Mechanik, FAU Erlangen-Nürnberg, Egerlandstraße 5, 91058 Erlangen, Germany 


\section{Introduction}

For the production of rotationally symmetric steel components - such as screws, bolts or axles — in large quantities, forward rod extrusion is used. By forming at room temperature, a high material and energy efficiency can be achieved. The high material strength compared to hot forming and the extensive work hardening during the component production lead to highly resilient components [13]. Additional challenges are caused by the processing of stainless steels, whose application is expected to increase. However, an inhomogeneous material flow occurring during forming leads to residual stresses remaining in the component after removal from the tool.

The superposition of residual stresses to the acting load stresses during component use can both enhance and impair the component properties. Since component failure under cyclic loading usually originates from the surface or nearsurface regions [30], residual stresses in this area are of particular relevance. In general, compressive residual stresses lead to an extension of the fatigue strength, while tensile residual stresses promote crack initiation and growth [29]. In order to remove any tensile residual stresses that may be present, formed components are often subjected to an energy-intensive heat treatment in which they are stress-relieved by annealing. A targeted adjustment of the residual stresses that are generated in the component during extrusion thus offers great potential for improving the component properties while shortening the process chain and improving the energy footprint by eliminating the need for heat treatment.

The residual stress state generated in the parts by forward rod extrusion depends on several factors. For residual stress measurement, various techniques are being used [12]. Usually, tensile stresses are detected at the surface of extruded parts [26]. qualitatively showed their presence. In [36], billets of $\mathrm{C} 15$, coated with phosphate and soap, were forward rod extruded, resulting in near-surface tensile stresses [27]. also observed tensile stresses at the surface of extruded rods for different experimental setups.

Since residual stresses are the result of inhomogeneous work hardening within the component, it is possible to alter the residual stress state by controlling the inhomogeneity. This can be done by additional finishing steps like shot peening [7] or another forming operation with a small diameter reduction [27]. Another method for manipulating the hardening inhomogeneity and therefore the component residual stresses is by altering the stress state during forming. In forward rod extrusion, this can be achieved by changing the overall material flow through the forming zone in the die. Influencing factors are the reduction of area in the billet and the material deflection in the die shoulder. Extensive research on the influence of the die opening angle and the extrusion ratio was carried out in [27], where tensile stresses were observed at the surface and compressive stresses could only be generated by a subsequent drawing step. Recent work has also focused on the use of a counter punch for stress state adjustment [15].

Another possibility for influencing the near-surface stress state is in the tribological system. A change in the friction between tool and workpiece causes a change in the near-surface shear stresses. This affects the work hardening in the edge layer and the inhomogeneity of the hardness in the component, which allows altering the near-surface residual stress state [32]. The tribological system consists of the tool and workpiece surfaces and the lubrication system as intermediate medium. In cold bulk forming, the distinct work hardening of the part material leads to temperatures of up to $500^{\circ} \mathrm{C}$ and pressures of up to $3500 \mathrm{MPa}$ between the part and the tool [21]. The primary objective in the use of lubricants is therefore the separation of die and workpiece surfaces to avoid tool wear [33]. However, to avoid tool fatigue, an additional aim is to achieve optimum lubrication in order to minimise the occurring process forces.

While recent developments aim at the use of ecologically benign coatings [1] or the complete omission of lubricants [3], the use of conventional lubricant coatings is inevitable in many applications. For complex forming operations involving high loads, two-phase lubrication systems are generally used, which consist of a carrier layer and a lubricant layer [2]. The lubricant carrier layer is designed to increase the surface area of the workpiece to enable the adhesion of a high quantity of lubricant. In the case of steel materials, it consists of zinc phosphate [1] and for corrosion-resistant stainless steel of iron oxalate [28]. Due to its high load bearing capacity and temperature stability [34], molybdenum disulphide $\left(\mathrm{MoS}_{2}\right)$ is usually preferred as a solid lubricant when forming stainless steel. In contrast, soaps and polymers are used for their improved sliding properties.

To determine tribological properties, there are various test set-ups, such as the sliding compression test [11], a combination of backward cup and rod forward extrusion [16] or the spike forging test as a combination of upsetting and backwards extrusion [20]. In bulk forming, the double cup extrusion (DCE) test is particularly suitable for the determination of the friction factor [4].

\section{Objectives and approach}

The overall objective is to systematically modify the residual stresses in components that occur after forward rod extrusion. In this paper, the influences of the control variables "lubrication" and "material flow" are to be investigated ex- 
perimentally. The underlying mechanisms for the former are to be examined by numerical simulations.

For the identification of tribological influences, the used tribological systems are characterized first. Billets made of ferritic stainless steel X6Cr17 (DIN 1.4016) are coated with a lubrication system consisting of iron-III-oxalate as carrier layer and three different lubricants. The friction factors are determined with the help of the double-cup-extrusion test. The influence of the lubricant on the component residual stresses is investigated by forward rod extrusion and subsequent X-ray stress measurement in the formed shaft. The effect of the material flow change is determined in forming experiments with three different die opening angles.

In view of the lack of a numerical model to date that can adequately resolve the residual stress state induced by full forward extrusion, a Finite Element (FE) model to address that is developed and validated via mesh and time-step sensitivity analyses. Modeling guidelines are derived regarding the choice of the fidelity of the FE-mesh for the billet and the time-step size for the forming phase that precedes that of ejection.

The outline of the paper is as follows. In the following section, the used tribological systems are shown and the results of the characterization with the DCE test are presented. In Sect. 4, the experimental setup and the results of the forward rod extrusion experiments are presented. The numerical model and the corresponding results from the numerical investigations are described in Sect. 5. Conclusions from the experimental and numerical investigations are drawn in Sect. 6 and a brief summary and outlook of the work are provided in Sect. 7.

\section{Identification of tribological properties}

In the cold forming of stainless steels, high surface pressures develop between the workpiece and the tool. For this reason, lubrication systems consisting of two parts are used. On the surface of the billets, an iron-III-oxalate layer is applied chemically, which acts as a carrier for the lubricant. The reference is a $\mathrm{MoS}_{2}$-based lubricant, since it is capable of separating surfaces at very high loads. For the determination of the influence of lubrication on residual stresses, a soap-based and a polymer-based lubricant are used. The coating of the billets used for the DCE tests and the forming experiments is performed by ZWEZ Chemie. For the oxalating, ZWEZ Coat 1039 is applied. The used lubricants are ZWEZ Lube MD $230\left(\mathrm{MoS}_{2}\right)$, ZWEZ Lube Z (soap) and ZWEZ Lube PD (polymer).

The friction factors of the used lubricants are identified numerically with DCE tests. In the DCE test [4], a moveable upper punch penetrates the billet, which is positioned on the fixed lower punch. The friction between the surface of the workpiece and the die bore, given by the used tribological system, influences the flow of material in the axial direction. In the theoretical case of no friction with $m=0$, the flow of material is not hindered, whereby symmetrical cups are formed on the upper and lower side of the billet. In the case of adherence, on the other hand, only the upper cup is formed. The approach for the determination of the friction factor consists of a numerical determination of the relations between friction factor and cup height ratio and an experimental setup for the determination of the latter. The basics of the method are shown in Fig. 1.

In the numerical part, the cup extrusion process is simulated in a parameterised numerical model. The aim is the identification between the friction factor $m$ as input and the resulting cup height ratios $r$ as output, which are corresponding to the ratio of upper cup to lower cup. For the simulation, the model validated in [19] is used in the software simufact.forming. The cup extrusion is simulated with different values of $m$ in the relevant range from 0 to 0.2 , where the friction factors are expected.
Simulation

Input: friction factor $m$

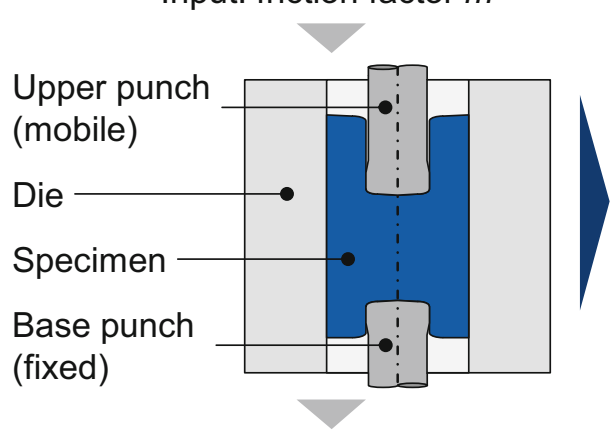

Output: cup height ratio $r$

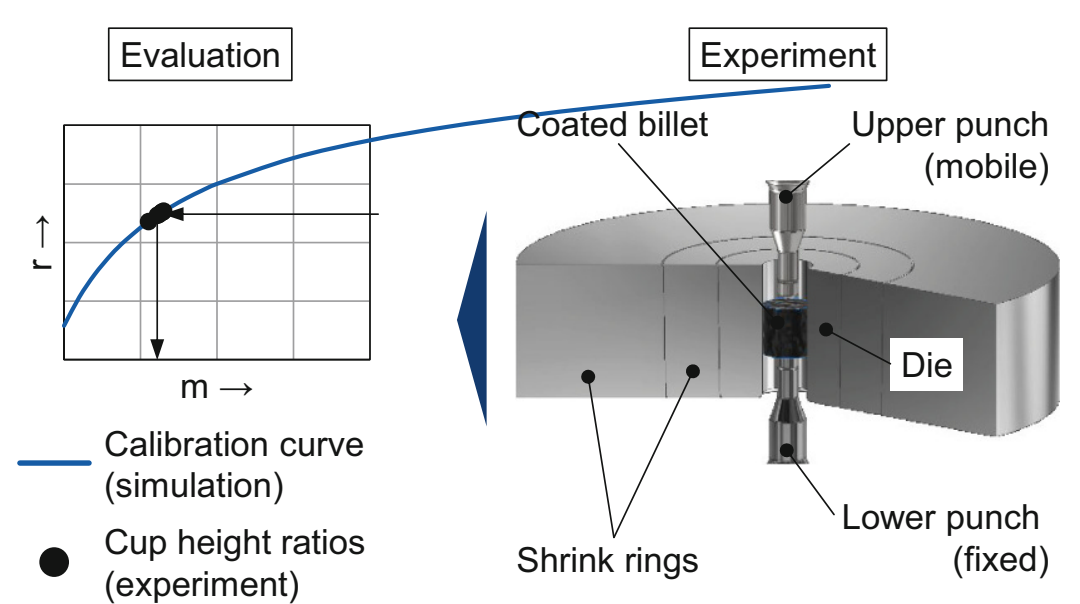

(experiment)

Fig. 1 Double cup extrusion test: Determination of the friction factor by numerical-experimental coupled approach 

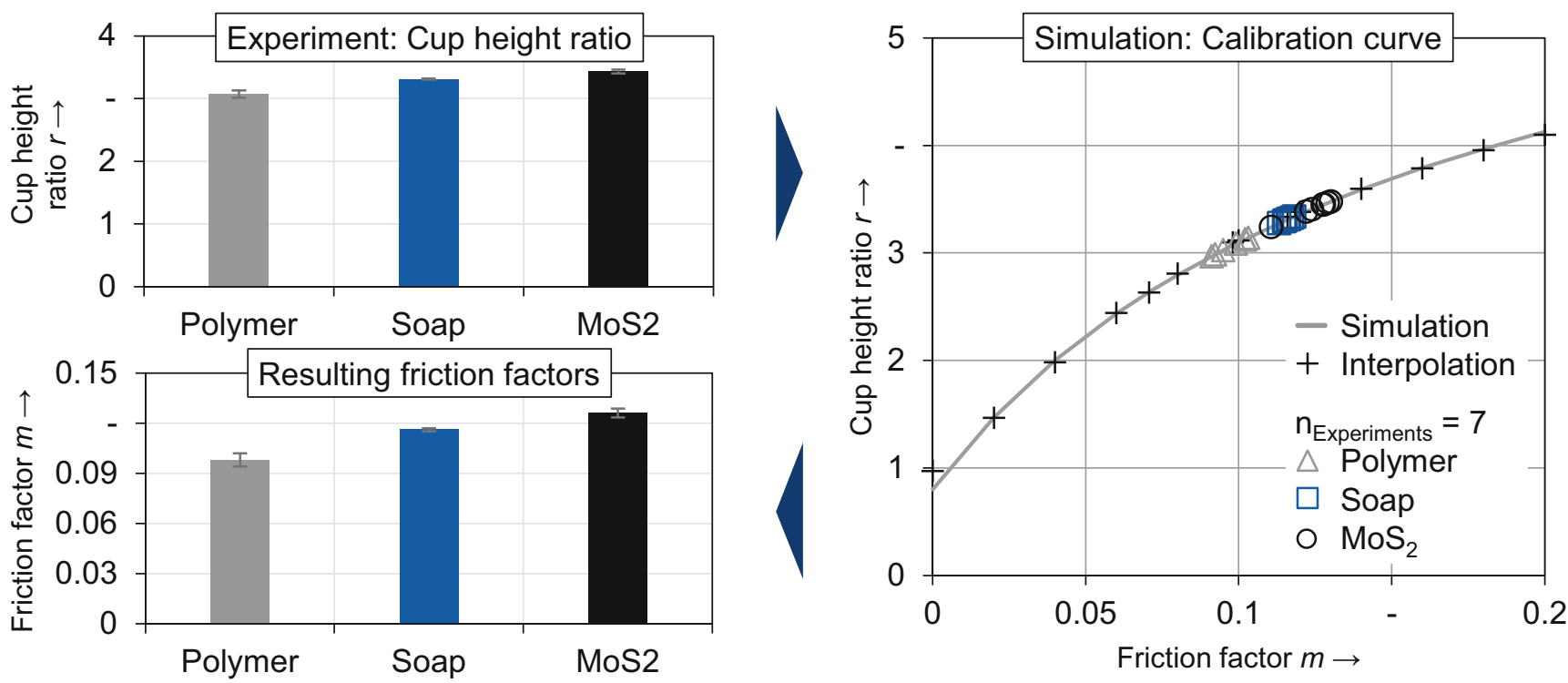

Fig. 2 Double cup extrusion test: Experimentally reached cup height ratios, numerically determined calibration curve and resulting friction factors

In the experimental section, the double-cup-extrusion is physically realised. In the process, billets coated with the tribosystem to be investigated are formed and the resulting cup height ratios are measured. The friction factor is then calculated with the help of the simulation-determined calibration curve. The experimental realisation takes place in an electromechanical testing machine Schenck-Trebel RM400. The die is made of quenched and tempered high-speed steel HS 2-2-2 with a honed bore-according to the forming die. It is pressed into two shrink rings made of hot working steel $\mathrm{X} 38 \mathrm{CrMoV} 5$ to limit its radial expansion. The specimens used for the DCE tests are coated in the same batch as the forming billets. To achieve reliable information, $n=7$ tests are carried out for each lubricant.

The determination of the friction factors present for each lubricant is carried out via a numerical identification with the calibration curve and a confirming simulation with the identified values. The results are shown in Fig. 2.

The use of the polymer-based lubricant leads the lowest cup height ratio $r$ of $3.071 \pm 0.056$. Soap shows a value of $3.311 \pm 0.011$ and $\mathrm{MoS}_{2}$ to $3.433 \pm 0.031$. With the numerically identified calibration curve, these experimentally determined values are corresponding to friction factors of $0.098 \pm 0.004$ for polymer, $0.116 \pm 0.001$ for soap and $0.126 \pm 0.003$ for $\mathrm{MoS}_{2}$. These differences between the lubricants are consistent with information from literature, such as [23], where $\mathrm{MoS}_{2}$ and polymer are compared. While polymer and soap have superior lubricating properties, $\mathrm{MoS}_{2}$ has advantages in separating part and tool surfaces under high load [34]. In [18], it is shown, that the use of soap and polymer leads to lower punch forces in forward rod extrusion compared to $\mathrm{MoS}_{2}$. The latter, however, is able to separate surfaces and provide lubrication even

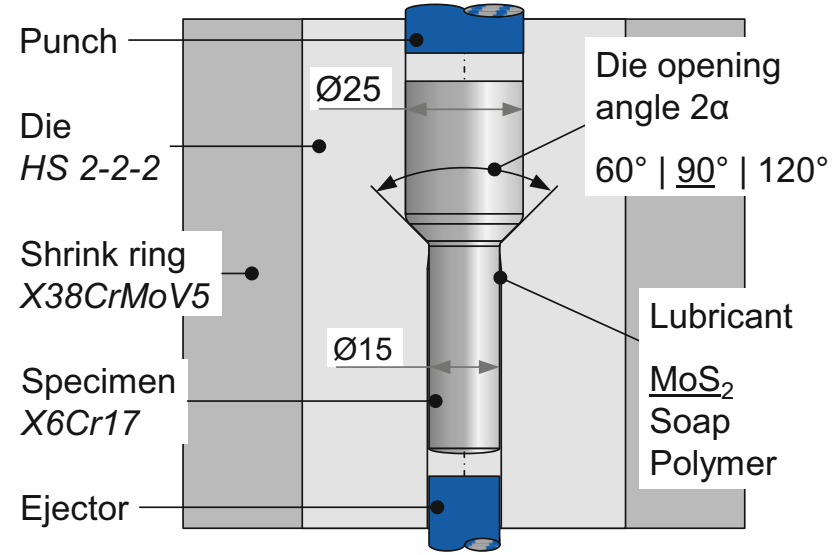

Fig. 3 Experimental setup and investigated variables for residual stress control

under high tribological loads, like in the forming of high strength duplex steels. Lower friction factors while using phosphate as lubricant carrier layer on typical cold forging steel 16MnCr5 like in [23] suggest that the use of stainless steel with an iron oxalate layer leads to elevated friction.

\section{Residual stress control by lubrication and material flow}

The influences of lubrication and material flow on the residual stresses in the formed shaft in forward rod extrusion are experimentally investigated. For this purpose, billets made of ferritic stainless steel X6Cr17 (DIN 1.4016) are forward rod extruded with the aforementioned three lubricants in forming dies with three different opening angles $2 \alpha$. In this 
section, both the setup and the results from the investigations are presented and discussed.

\subsection{Process setup}

For part production, billets are coated with the three lubrication systems shown in Sect. 3. Forming takes place with a representative forward rod extrusion process, which is shown with the investigated control variables in Fig. 3. The diameter of the billets is reduced from 25 to $15 \mathrm{~mm}$, which corresponds to an equivalent plastic strain of $\bar{\epsilon} \simeq 1$. 0 . The forming zone of the dies is conical with a reference shoulder angle of $2 \alpha=90^{\circ}$. For the alteration of the material flow and the identification of its influences, dies with opening angles of $2 \alpha=60^{\circ}$ and $2 \alpha=120^{\circ}$ are used.

The experiments are performed with a hydraulic press type Lasco TZP400. For forming, extrusion dies made of quenched and tempered high-speed steel $H S$ 2-2-2 with an extruder-honed die bore are used. In order to limit the radial expansion during forming and to increase their lifetime, the dies are pressed into shrink rings made of hot working steel X38CrMoV5. To ensure comparability, all dies have the same transition radii and were subjected to the same heat and surface treatment. After forming, the parts are ejected in the opposite to the punch direction.

For residual stress measurement, X-ray diffraction is used, as it allows a non-destructive and fast stress quantification. On the formed shaft of the parts, the near-surface residual stresses are determined with the 8-axis X-ray diffractometer Seifert XRD 3003. A detailed overview of the measuring setup used is given in [17]. The measurement is performed at the $\left\{\begin{array}{lll}2 & 1 & 1\end{array}\right\}$ lattice plane of the ferritic microstructure using $C r \mathrm{X}$-radiation and the $\sin ^{2} \Psi$-method. The X-ray radiation is guided through a glass capillary op-

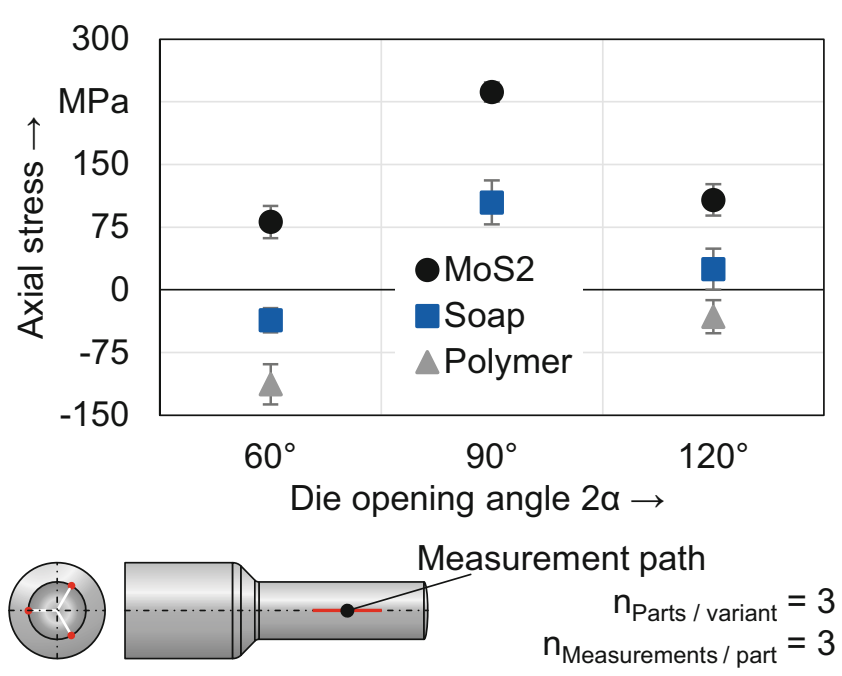

Fig. 4 Experimentally determined axial residual stresses in the formed shaft tic and an aperture with a diameter of $1.5 \mathrm{~mm}$, resulting in a spot diameter of approximately $0.8 \mathrm{~mm}$. This size ensures that no mathematical correction is required due to the curved surface of the specimen [9]. The peaks are recorded with a line detector Meteor $1 D$ under two azimuth angles using the $\chi$-method with six tilts each in the positive and negative $\psi$-direction. The calculation of the residual stresses takes place in the software RayfleX Analyze. The determination of the line positions from the recorded peaks is done using a pseudo-Voigt function. For the calculation of the residual stresses, the X-ray elasticity constants from [6] are used. An overview of possible error source variables is given in [31], but in general a texture uncertainty of up to $30 \mathrm{MPa}$ is assumed [24].

\subsection{Results}

With this setup, experimental investigations of the process were carried out. In the following, the results of forming with the reference setup with a die opening angle of $2 \alpha=90^{\circ}$

and the $\mathrm{MoS}_{2}$-based lubricant are analysed first in order to generate an understanding of the process. This is followed by an analysis of the influences of the die opening angle and the lubricant. The experimentally determined residual stress state of the reference parts is presented in Fig. 9, together with the corresponding results from the numerical model. The standard deviation in the measured stresses is about $\pm 40 \mathrm{MPa}$, of which $\pm 20 \mathrm{MPa}$ is due to common inaccuracy of the $\mathrm{x}$-ray diffraction method [10].

Since a constant residual stress state is found along the shaft (cf. Fig. 9), the values from this range is addressed in the following. The influences of the used lubricants and the die opening angles on process forces and part temperatures are investigated in [18]. The effects on the near-surface residual stresses are shown in Fig. 4. In this context, only the axial stresses are considered, as the measurements in tangential direction showed a similar stress state for all variants and tangential stresses are of minor importance in the mechanical loading of components. The values and deviation bars in the figure refer to the mean value from three measuring paths on three samples each, resulting in a total of nine measurements per variant.

The use of $\mathrm{MoS}_{2}$ with a friction factor of $\mathrm{m}=0.126$ leads to the highest residual stresses, which are in the tensile range for all die opening angles. A gradual reduction of the friction by the use of soap with $\mathrm{m}=0.116$ and polymer with $\mathrm{m}=0.098$ leads to a shift in the direction of compressive stresses. The use of polymer with the lowest friction factor leads to compressive residual stresses for $2 \alpha=60^{\circ}$ and $120^{\circ}$. The variants with polymer and $2 \alpha=90^{\circ}$ have not been formed due to die failure in previous experiments. However, based on the values for the two variants performed, a value around $0 \mathrm{MPa}$ is expected here. This reduction of 


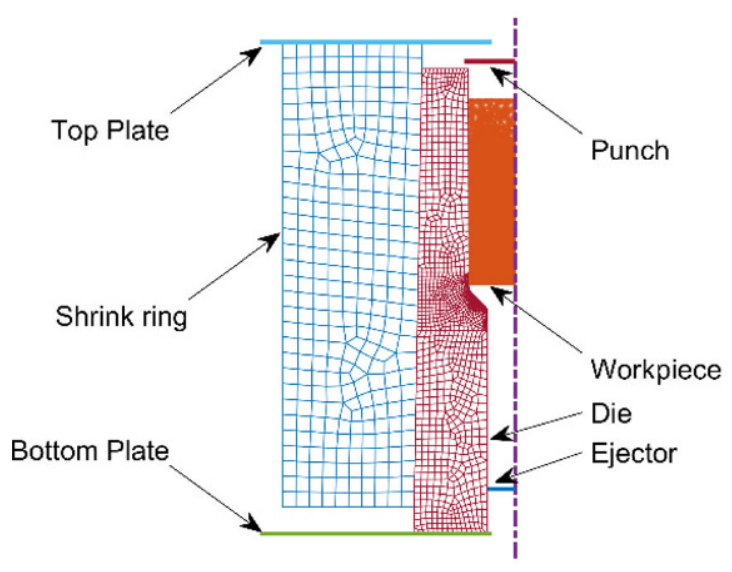

b

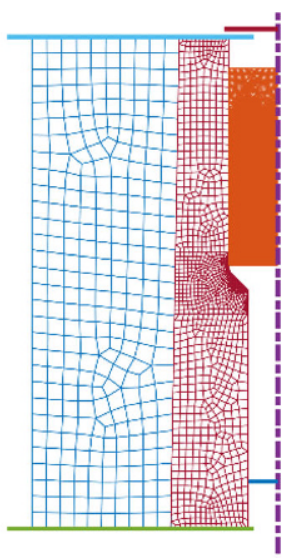

C

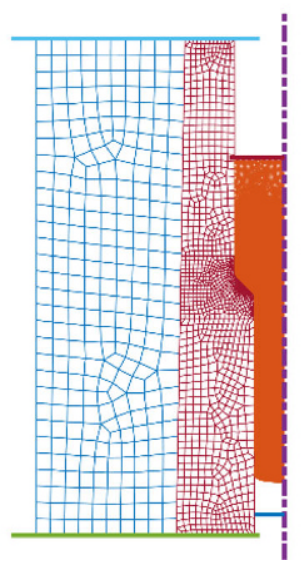

d

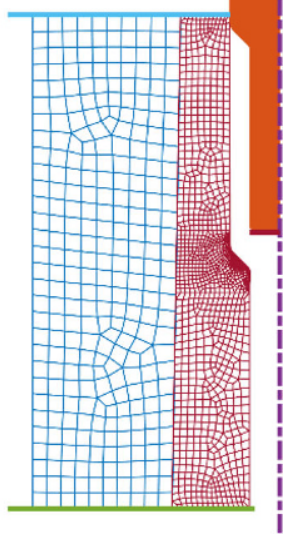

Fig. 5 Numerical model for full forward extrusion. a Model parts, b Load case 1: Shrink ring-die pressure, $\mathbf{c}$ Load case 2: Forming, d Load case 3: Ejection

the near-surface stresses can be explained by improved sliding properties and therefore reduced shear stresses, leading to a decreased inhomogeneity of the plastic deformation in the surface and near-surface areas of the extruded parts.

With a die opening angle of $2 \alpha=90^{\circ}$, the highest residual stresses are measured, cf. Fig. 4. Both a reduction and an increase of the shoulder angle lead to a reduction of the tensile stresses or a shift to compressive stresses. This shift is more pronounced for $2 \alpha=60^{\circ}$ than for $120^{\circ}$.

\section{Modeling of full forward extrusion}

A 2D large strain axisymmetric FE-model for full forward extrusion in the commercial FE-analysis software MSC Marc [25] is further elaborated here using the model developed by the authors in [22] and optimized in [8] as a point of departure. The model is comprised of the continuum parts, shrink ring, die and workpiece, as well as the rigid parts, bottom plate, top plate, punch and ejector, see Fig. 5a. The continuum parts are discretized into bilinear quadrilateral elements with full integration (element label 10 in Marc). The geometry of all the parts is explic-

Table 1 Material model parameters for the continuum parts of the FEmodel

\begin{tabular}{llll}
\hline Part & Material & Elastic parameters & Plastic parameters \\
\hline Work- & X6Cr17 & $E=210000 \mathrm{MPa}$ & $\sigma_{y}=263.74 \mathrm{MPa}$ \\
piece & $(1.4016)$ & $v=0.28$ & $\begin{array}{l}R_{\infty}=195.421 \mathrm{MPa}, \\
b=6.11767\end{array}$ \\
& & $\begin{array}{l}C=9899 \mathrm{MPa} \\
\end{array}$ & $\begin{array}{l}\gamma=85.8351 \\
\text { Die }\end{array}$ \\
& ASP2012 & $\begin{array}{l}E=220000 \mathrm{MPa} \\
v=0.30\end{array}$ & N/A \\
Shrink & X37CrMoV5 & $\begin{array}{l}E=210000 \mathrm{MPa} \\
v=0.30\end{array}$ & N/A \\
ring & & & \\
\hline
\end{tabular}

itly defined via "points" and "curves" from the "geometry and mesh" toolbox that is available in the Mentat GUI. This allows for an effortless and consistent refinement of the FE-mesh of the workpiece using the advancing front method. More specifically, three FE-meshes are considered for the workpiece featuring 25,248 (coarse), 42,912 (fine) and 67,450 (finest) degrees-of-freedom. In contrast to [22] and [8], where a process-adapted mesh was used, a regular FE-mesh for the workpiece comprised mostly of rectangular elements is used here to resolve the full forward extrusion problem. Fixed and relatively coarse discretizations are considered for the shrink ring and the die with a finer mesh for the latter in the shoulder region.

The built-in Marc Chaboche [5] combined nonlinear isotropic/kinematic hardening model is used as a constitutive model for the workpiece with the model parameters identified in [8] based on compression-tension-compression uniaxial stress experiments, see Table 1. This is an improved constitutive modeling approach compared to the pure isotropic hardening model used in [22]. The die and the shrink ring are modeled as linear elastic with the parameters provided in Table 1 .

The aforementioned model parts are defined as deformable and geometric contact bodies in Marc. The boundaries of the deformable parts are analytically defined via cubic splines. Normal/frictional contact between corresponding model parts is resolved via a node-to-segment contact discretization and the shear (bilinear) friction model using the default method in Marc for enforcing contact constraints. The friction factor is set to $\mathrm{m}=0.10$ for the contact between rigid and deformable parts (as proposed in [14]) and $m=0.06$ for the die-shrink ring interface. A bias factor of 0.99 is used to limit the contact tracing only to nodes that penetrate a contacting body. In addition, the "chattering" during Newton iterations in 
the same incremental step is suppressed to improve the convergence properties of the nonlinear problem at hand. The default choices in Marc are used for all the remaining contact parameters.

Full forward extrusion is modeled in three load steps ("load cases" in Marc). In the first step (Fig. 5b), the shrink ring with an oversize of $5 \%$ (equates to a radial distance of $0.125 \mathrm{~mm}$ ) is displaced downwards while in contact with the die via contact with the top plate. In the second step (Fig. 5c), the upper surface of the workpiece is displaced some $22.0 \mathrm{~mm}$ downwards through the opening of the die via contact with the punch. In case the ejection phase is not modeled, unloading of the workpiece is the final step after forming by removal of all the relevant contact sites. In case the ejection phase is modeled, the workpiece is displaced $60.0 \mathrm{~mm}$ upwards through the die via contact with the ejector (see Fig. 5d). Throughout all the steps, symmetry boundary conditions are enforced at the inner radius of the (half due to axisymmetry) workpiece (see Fig. 5a). The displacement of the shrink ring in the radial direction at the outer radius is restrained from the second load step and on. At the unloading step, the pertinent rigid body motion of all the continuum parts is suppressed. In the numerical investigations that follow, the reference values from Sect. 4.1 are chosen for the forming parameters, namely a die opening angle of $2 \alpha=90^{\circ}$ and a friction factor $m=0.126$ for the die-workpiece interface corresponding to the $\mathrm{MoS}_{2}$-based lubricant.

\subsection{Forming without ejection}

Due to the complexity associated with the modeling of forming followed by ejection, the developed FE-model was first used to simulate forming without ejection. The experimentally measured residual stresses for that case are adopted from [22]. The resolved forming induced residual stress state in the workpiece for the finest mesh is illustrated in Fig. 6a. Tensile residual stresses of approximately $400 \mathrm{MPa}$ form in the near-surface region and compressive

Fig. 6 a Numerically determined residual stress state $\left(\mathrm{MoS}_{2}\right.$-based lubricant and die opening angle, $2 \alpha=90^{\circ}$ ), b Measurement path, c Nearsurface residual stresses in the core region of the formed shaft. Near the shoulder of the component, compressive stresses develop, which are due to the material deflection at the die shoulder. Measured and numerically determined axial residual stresses along the measurement path depicted in Fig. 6b are compared in Fig. 6c. A very satisfactory prediction of the residual stress state is observed. This is further elaborated in the remainder of the current section. The predicted stresses presented in Fig. 6 as well as in all the figures that follow were determined by nodal (weighted) averaging of the stresses at neighboring integration points.

The sensitivity of the residual stresses predicted by the model to the number of time steps for the forming load case (Fig. 5c) is depicted in Fig. 7a for the coarse mesh and in Fig. 7b for the fine mesh. A time-step size of 0.001 corresponds to some $0.044 \mathrm{~mm}$ distance done by the punch in contact with the workpiece. The residual stresses in both discretizations appear almost unaffected by the time-step size. This implies that relatively large time-step sizes may be chosen when modeling the forming without ejection without affecting the accuracy of the model.

The effect of the fidelity of the FE-mesh of the workpiece on the residual stresses predicted by the model is illustrated in Fig. 8. Although convergence with mesh refinement is not decisively concluded from the graphs, the relative change (increase) in the residual stresses with mesh refinement decreases as finer meshes are considered. Nevertheless, the predicted residual stresses are of satisfactory accuracy even for the coarsest mesh. This, combined with the conclusion drawn above regarding the choice of the time-step size for the forming load case, provide the FE-analyst with a large degree-of-freedom regarding the aforementioned modeling choices.

\subsection{Forming with ejection}

Having established in Sect. 5.1 that a robust FE-model of full forward extrusion is at hand, model parameter investigations were performed for the case of forming followed a

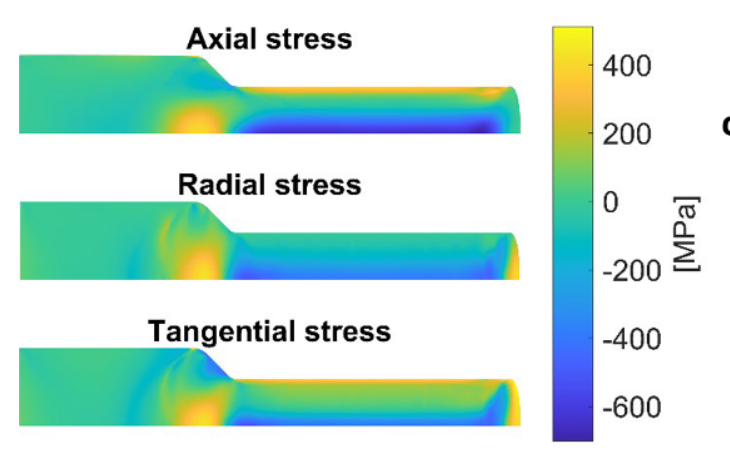

b

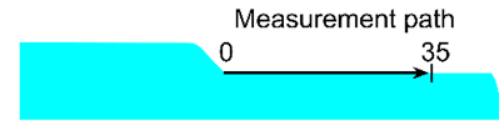

C

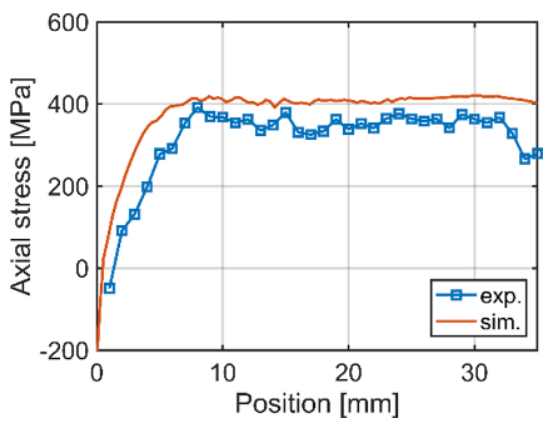


Fig. 7 Effect of the time step size for the forming load case on residual stresses. a Coarse mesh, b Fine mesh
Fig. 8 Effect of FE-mesh size on residual stresses for a fixed time step size of 0.0001. a Axial stress, b Tangential stress
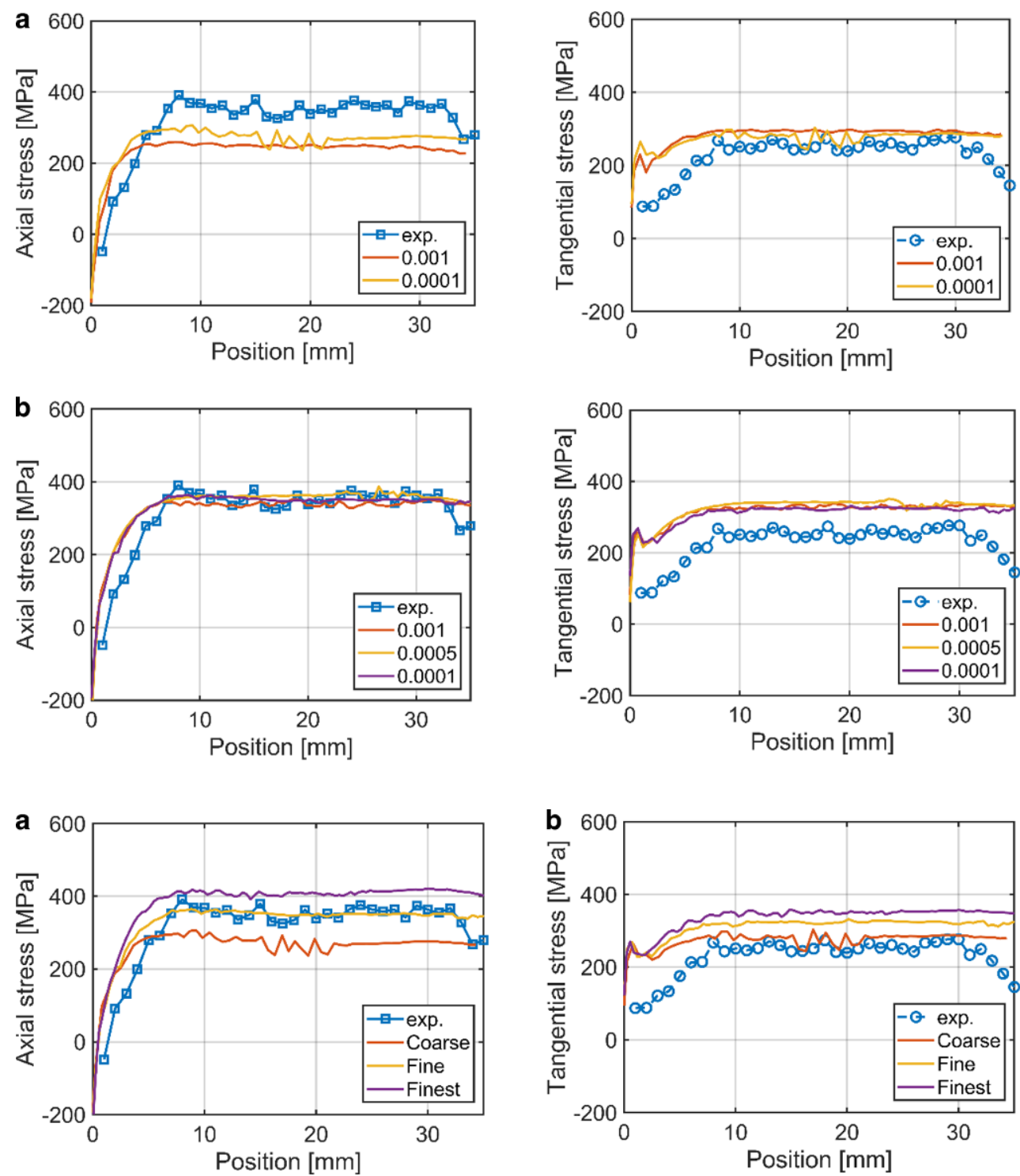

by ejection (see Fig. 5d) of the workpiece. The experimental results for this case correspond to the reference case of $2 \alpha=90^{\circ}$ and $m=0.126$ from Sect. 4 . The effect of the timestep size for the forming load case on residual stress predictions after ejection is displayed in Fig. 9a, b for the coarse and fine FE-discretizations, respectively. A pronounced effect of the parameter is observed in both discretizations. More specifically, a tenfold reduction of the time-step size in the coarse mesh results in a good prediction of the axial stress component and a divergence of the tangential stress component compared to the measurements. As regards fine mesh, the prediction of the axial stress component improves with a decreasing time-step size, whereas the tangential component appears almost invariant to the time-step size and close to the experimentally determined values. Exception to the latter is the near-shoulder region $(0-10 \mathrm{~mm})$ for the time-step size 0.0005 . However, the prediction improves with a further decrease in time-step size to 0.00005 .

Results on the effect of the same model parameter on the finest mesh are shown in Fig. 10. In that case, the agreement between measured and predicted axial residual stresses improves only marginally with significant refinement of the time-step size for forming. The tangential stress component appears converged to a value that is in close agreement with the experiment. It is thus concluded from Figs. 9 and 10 that convergence with mesh and temporal refinements is not yet obtained for the highest examined mesh and time step resolutions. Moreover, even if the model with the finest mesh will converge with excessive time-step refinement, the computational cost to accomplish that appears to be high. In lack of a fully robust model of the forming with ejection for the reference die opening angle of $2 \alpha=90^{\circ}$, no further numerical investigations were performed for the die open- 
Fig. 9 Effect of time step size for the forming load case on residual stresses. a Coarse mesh, b Fine mesh
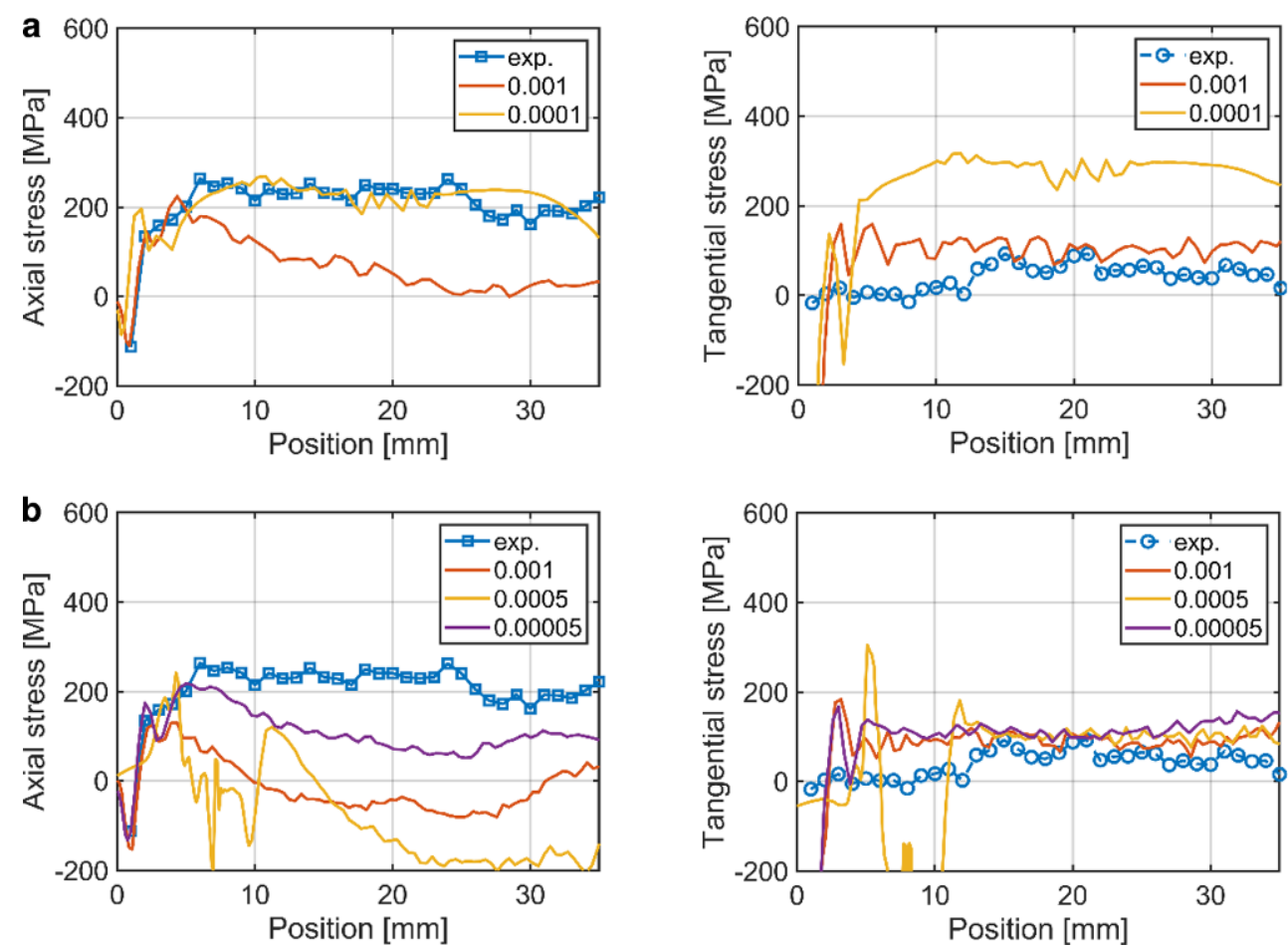

Fig. 10 Effect of time step size for the forming load case on residual stresses for the finest mesh

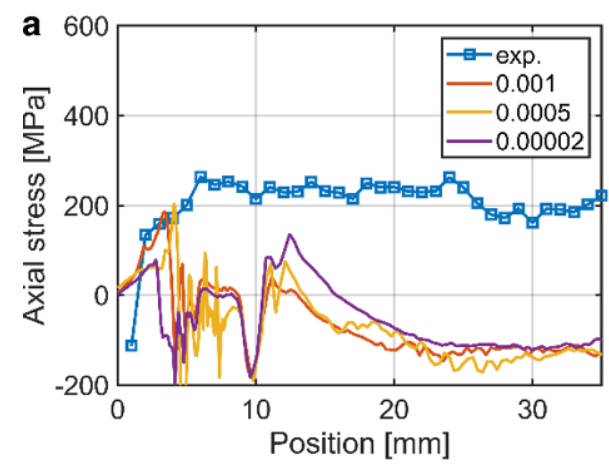

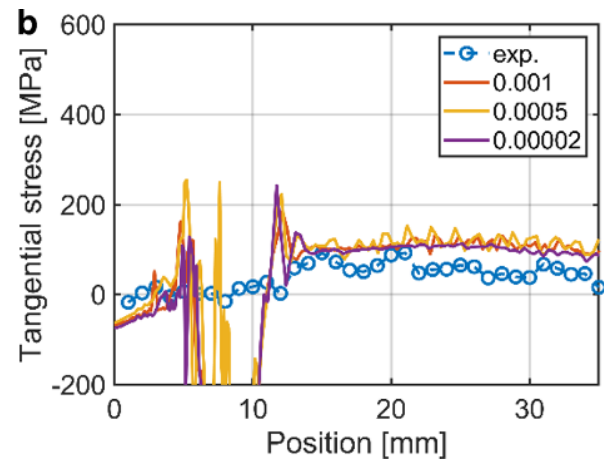

ing angles of $2 \alpha=60^{\circ}$ and $2 \alpha=120^{\circ}$ that were otherwise experimentally investigated in Sect. 4.

During the ejection phase, the die undergoes elastic springback resulting into contact with the thinner shaft of the workpiece. Based on the preceding analyses, the choice of the time-step size for the forming load case has a significant influence on the model prediction of the residual stress state after ejection. This may be viewed as the requirement to resolve the pertinent contact problem during the ejection phase that the shape of the workpiece after forming be adequately resolved. With the correct deformed configuration for the workpiece after forming at hand, the chances that the right contact problem between the workpiece and the die is actually resolved during ejection are increased.

Potential remedies for obtaining a robust and efficient FE-model for the case of forming with ejection are discussed here. More specifically, the use of a constitutive model for the workpiece dedicated to large strain plastic- ity, see e.g. [35], is considered by the authors as a measure towards the improved modeling of the forming phase. It is expected to yield a more accurate deformed shape for the workpiece after forming and, consequently, an improved precondition for resolving a more representative problem during the ejection phase, than the one achieved with the considered Chaboche model.

In addition to the improved constitutive modeling described above, a remedy to increase the computational efficiency of the simulations of forming with ejection is needed. In this regard, it may be advantageous to treat the forming and ejection phases to some extent separately. That is, since the residual stress predictions by the developed model for the case of forming without ejection were shown to be accurate and insensitive to the chosen spatial and temporal discretizations, the state variables at the integration points of the FE-mesh of the workpiece obtained for rather coarse discretizations may be stored at the end of the 
Fig. 11 Effect of varying the lubrication (friction factor) on predicted residual stresses for the die opening angle $2 \alpha=90^{\circ}$, fine mesh and a fixed time step size of 0.00005 . a Axial stress, b Tangential stress

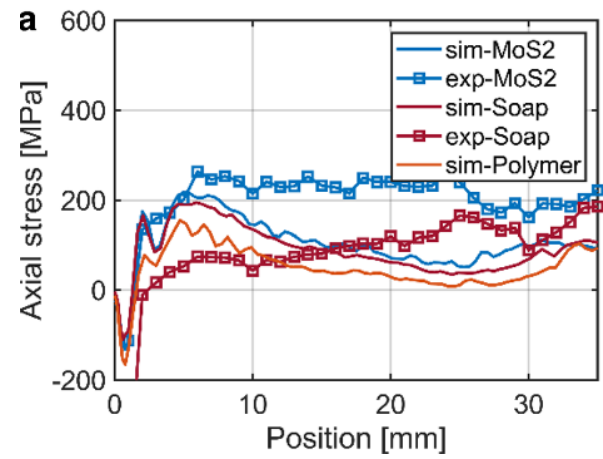

forming phase and used as initial state for the modeling of the ejection phase in a separate analysis. In the latter, the exact geometry of the workpiece at the end of the forming phase may be used, as measured in experiments, and the stored state variables be mapped onto the new FE-mesh of the workpiece. With the proposed modeling strategy, the modeling of the forming phase needs to be performed only once at a relatively low computational cost and the ejection phase is thereafter modeled with the exact deformed shape of the workpiece after forming.

\subsubsection{Effect of lubrication}

Although the preceding spatial and temporal discretization analyses with the developed model of full forward extrusion-and-ejection are not entirely conclusive, the model with the fine mesh was used to study the effect of a varying lubrication (friction factor) on predicted residual stresses for the reference die opening angle $2 \alpha=90^{\circ}$. The results are displayed in Fig. 11. Although the exact measured values are not captured by the model, the decreasing trend in the axial stress component with decreasing friction factor reported in the experiments (cf. Sect. 4.2) is clearly observed in the predictions, see Fig. 11a. The predicted tangential stress component in Fig. 11b is provided for completion.

\section{Conclusions}

Combined numerical and experimental investigations of forward rod extrusion of ferritic steel X6Cr17 were carried out. From the presented results, the following conclusions can be drawn.

- Near-surface tensile residual stresses can be reduced or even shifted to compressive stresses by using lubricants with reduced friction between workpiece and tool.

- The decreasing trend in residual stresses was also verified by the numerical model.

- Forming with a die opening angle of $2 \alpha=90^{\circ}$ leads to the highest observed tensile stresses; the use of higher or lower shoulder angles leads to a decrease of the part residual stresses and may even cause a shift to compressive stresses.

- A robust numerical model of full forward extrusion is at hand for the prediction of the forming induced residual stress state for the case of forming without ejection.

- The robustness of the model for the case of forming with ejection is inconclusive and further investigations as well as an elaborate modeling approach are be required for computational efficiency.

- Although a negligible effect of the time-step size for forming on predicted residual stresses was observed in the forming simulations (without ejection), a profound effect from the same parameter was observed on the predicted residual stresses after ejection.

\section{Summary and outlook}

Inhomogeneous stress states during forming lead to residual stresses in the produced parts, which may influence their corrosion and fatigue behaviour. Tensile residual stresses after forward rod extrusion need to be eliminated by annealing or other subsequent process steps. A targeted adjustment of the residual stresses during forming therefore enhances both the product properties and its ecological footprint.

In this paper, the objective was to identify influences of the used lubrication system and the material flow on the residual stresses. Due to the industrial relevance, the research is performed with a forward rod extrusion process of ferritic stainless steel X6Cr17 (DIN 1.4016). Three lubricants-MoS2, soap and polymer-are used for the investigations. The influences of the material flow are identified by forming in conical dies with three different die opening angles of $2 \alpha=60^{\circ}, 90^{\circ}$ and $120^{\circ}$.

The tribological properties of the lubricants were characterized using the double cup extrusion test. With this method, friction factors were identified in the range of 0.098 to 0.126 , with polymer having the lowest and MoS2 having the highest value. The forming experiments revealed a decrease of the near-surface tensile stresses with decreas- 
ing friction for all shoulder angles used. This was verified by numerical simulations in the examined case of $2 \alpha=90^{\circ}$. A die opening angle of $2 \alpha=90^{\circ}$ has led to the highest experimentally measured tensile residual stresses. Both an increase and a decrease of the shoulder angle resulted in reduced tensile stresses and even a shift to compressive stresses. Based on the experimental and numerical results, the recommendation was derived to reduce friction in forward rod extrusion for an enhancement of the residual stress state.

In further research work, not only the influences of control variables, but also the effects of disturbances on residual stresses are to be investigated. In particular, variations in the tribosystem and in the mechanical properties of the raw material are of interest. In addition, the modeling of forming-and-ejection needs to be elaborated such that the correct shape of the formed component is at hand prior to ejection, a factor that may lead to residual stress predictions of increased accuracy. This may be achieved by the consideration of a constitutive model for the workpiece that is dedicated to large strain plasticity.

Acknowledgements The research activities are funded by the Deutsche Forschungsgemeinschaft (DFG, German Research Foundation) within the scope of the priority program SPP2013-Targeted Use of Forming Induced Residual Stresses in Metal Components in the subproject P10 (project number: 374688875).

Funding Open Access funding enabled and organized by Projekt DEAL.

Conflict of interest A. Jobst, D. Floros, P. Steinmann and M. Merklein declare that they have no competing interests.

Open Access This article is licensed under a Creative Commons Attribution 4.0 International License, which permits use, sharing, adaptation, distribution and reproduction in any medium or format, as long as you give appropriate credit to the original author(s) and the source, provide a link to the Creative Commons licence, and indicate if changes were made. The images or other third party material in this article are included in the article's Creative Commons licence, unless indicated otherwise in a credit line to the material. If material is not included in the article's Creative Commons licence and your intended use is not permitted by statutory regulation or exceeds the permitted use, you will need to obtain permission directly from the copyright holder. To view a copy of this licence, visit http://creativecommons.org/licenses/by/4. $0 /$.

\section{References}

1. Bay N, Azushima A, Groche P, Ishibashi I, Merklein M, Morishita H, Nakamura T, Schmid S, Yoshida M (2010) Environmentally benign tribo-systems for metal forming. CIRP Ann Manuf Technol 59(2):760-780. https://doi.org/10.1016/j.cirp.2010.05.007

2. Bay N (2013) New tribo-systems for cold forming of steel, stainless steel and Aluminium alloys. In: Proceedings of 46th International Cold Forging Group (ICFG) Plenary Meeting [7-04] International Cold Forging Group

3. Bergs T, Hild R, Feuerhack A, Müller M, Bobzin K, Brögelmann T, Kruppe N, Hoffmann D (2019) Modellierung des Tribosystems beim trockenen Vollvorwärtsfließpressen mithilfe eines erweiterten Reibmodells. Dry Met Form Open Access J Fast Manuscr Track 5:1-8

4. Buschhausen A, Weinmann K, Lee JY, Altan T (1992) Evaluation of lubrication and friction in cold forging using a double backward-extrusion process. J Mater Process Technol 33(1-2):95-108. https://doi.org/10.1016/0924-0136(92)90313-H

5. Lemaitre J, Chaboche JL (1998) Mechanics of solid materials. Cambridge University Press,

6. Eigenmann B, Macherauf E (1996) öntgenographische Untersuchung von Eigenspannungen in Werkstoffen, Teil III. Mater Sci Eng 27:426-437. https://doi.org/10.1002/mawe.19960270907

7. Farrahi GH, Lebrun JL, Couratin D (1995) Effect of shot peening on residual stress and fatigue life of a spring steel. Fat Fract Eng Mat Struct 18(2):211-220. https://doi.org/10.1111/j.1460-2695. 1995.tb00156.x

8. Floros D, Jobst A, Kergaßner A, Merklein M, Steinmann P (2021) Towards an holistic account on residual stresses in full-forward extruded rods. Arch Appl Mech. https://doi.org/10.1007/s00419-02101917-1

9. Francois M, Dionnet B, Sprauel JM, Nardou F (1995) The influence of cylindrical geometry on X-ray stress tensor analysis-I. General formulation. J Appl Crystallogr 28:761-767. https://doi.org/10. 1107/S0021889895006868

10. Fu X, Niu Z, Ding Y, Zhang J, Liu C, Chen Q, Li Z, Zhou W (2019) Accuracy of X-ray diffraction measurement of residual stresses in shot peened titanium alloy samples. Nondestruct Test Eval 34:164-177. https://doi.org/10.1080/10589759.2019.1573239

11. Groche P, Müller C, Jahn A (2014) Effects of the tool lubrication in cold forging. Tribol Lett 53(3):599-605. https://doi.org/10.1007/ s11249-014-0297-0

12. Guo J, Fu H, Pan B, Kang R (2019) Recent progress of residual stress measurement methods: a review. Chin J Aeronaut. https:// doi.org/10.1016/j.cja.2019.10.010

13. Hering O, Tekkaya AE (2020) Damage-induced performance variations of cold forged parts. J Mater Process Technol 279:116556. https://doi.org/10.1016/j.jmatprotec.2019.116556

14. Hinkfoth R (2003) Bulk forming processes. Verlagshaus Mainz, Aachen

15. Hoche H, Balser A, Oechsner M, Franceschi A, Groche P (2019) Verbesserung des Eigenspannungszustands beim Kaltfließpressen durch den aktiven Einsatz eines gesteuerten Gegenstempels. Mater Sci Eng 50:669-681. https://doi.org/10.1002/mawe.201900050

16. Hu C, Qiang Y, Zhao Z (2017) A novel method for determining friction in cold forging of complex parts using a steady combined forward and backward extrusion test. J Mater Process Technol 249:57-66. https://doi.org/10.1016/j.jmatprotec.2017.06.001

17. Jobst A, Kiener C, Merklein M (2019) Investigations on residual stress generation in extruded steel components. In: Wulfsberg JP, Hintze W, Behrens BA (eds) Production at the leading edge of technology, pp 83-92 https://doi.org/10.1007/978-3-662-60417-5_8

18. Jobst A, Merklein M (2020) Applicability of solid lubricant coatings in cold rod extrusion of stainless steels. Defect Diffus Forum 404:95-100. https://doi.org/10.4028/www.scientific.net/DDF. 404.95

19. Kiener C, Neher R, Merklein M (2018) Influence of tribological conditions on cold forging of gears. Prod Eng 12:367-375. https:// doi.org/10.1007/s11740-017-0785-9

20. Kim JH, Ko BH, Kim JH, Lee KH, Moon YH, Ko DC (2020) Evaluation of friction using double cup and spike forging test for dry-inplace coating and forming oils. Tribol Int 150:106361. https://doi. org/10.1016/j.triboint.2020.106361

21. Klocke F (2017) Fertigungsverfahren 4-Umformen. Springer, Berlin, Heidelberg, New York https://doi.org/10.1007/978-3-66254714-4 
22. Landkammer P, Jobst A, Kiener C, Steinmann P, Merklein M (2019) Investigations on residual stress generation in full-forwardextrusion. Prod Eng Res Devel 13:169-180. https://doi.org/10. 1007/s11740-019-00892-5

23. Lorenz R, Hagenah H, Merklein M (2018) Experimental evaluation of cold forging lubricants using double-cup-extrusion-tests. Mater Sci Forum 918:65-70. https://doi.org/10.4028/www.scientific.net/ MSF.918.65

24. Martina F, Roy MJ, Szost BA, Terzi S, Colegrove PA, Williams SW, Withers PJ, Meyer J, Hofmann M (2016) Residual stress of asdeposited and rolled wire+arc additive manufacturing Ti-6Al-4V components. Mater Sci Technol 32(14):1439-1448. https://doi.org/ 10.1080/02670836.2016.1142704

25. MSC MARC (2017) User guide. Version 2017

26. Midha PS, Madlen GF (1976) Residual stress relief in cold-extruded rod. Met Technol 3(1):529-533. https://doi.org/10.1179/ 030716976803392231

27. Midha PS, Madlen GF (1976) Residual stresses in cold-extruded rods. Met Technol 3(1):202-207. https://doi.org/10.1179/ 030716976803391962

28. Narayanan RG, Gunasekera JS (2019) Sustainable material forming and joining. CRC Press, New York https://doi.org/10.1201/ 9781315163147

29. Nelson D (1982) Effects of residual stress on fatigue crack propagation. In: Throop J, Reemsnyder H (eds) STP776-EB residual stress effects in fatigue, pp 172-194 https://doi.org/10.1520/STP30104S
30. Schijve J (2009) Fatigue of structures and materials. Springer, Dordrecht https://doi.org/10.1007/978-1-4020-6808-9

31. Spieß L, Teichert G, Schwarzer R, Behnken H, Genzel C (2009) Moderne Röntgenbeugung. Vieweg+Teubner, Wiesbaden https:// doi.org/10.1007/978-3-8349-9434-9_5

32. Tekkaya AE (1986) Ermittlung von Eigenspannungen in der Kaltmassivumformung. Dissertation, Universität Stuttgart https://doi. org/10.1007/978-3-642-82799-0

33. Teller M, Prünte S, Ross I, Küpper M, Poprawe R, Häfner C, Schneider J, Hirt G (2020) Lubricant-free tribology concepts for cold extrusion by interaction-reduced surfaces. Dry Met Form Open Access J Final Proj Report 6:166-191

34. Vazirisereshk MR, Martini A, Strubbe DA, Baykara MZ (2019) Solid lubrication with $\mathrm{MoS}_{2}$ : a review. Lubricants 7:57. https://doi. org/10.3390/lubricants7070057

35. Vladimirov IN, Pietryga MP, Reese S (2008) On the modelling of non-linear kinematic hardening at finite strains with application to springback-Comparison of time integration algorithms. Int J Numer Methods Eng 75(1):1-28. https://doi.org/10.1002/nme.2234

36. Zucko M, Pöhlandt K, Pyzalla A, Reimers W, Kockelmann H (1997) Berechnung der Umformeigenspannungen beim Fließpressen und Vergleich mit experimentellen Ergebnissen. Mater Sci Eng 28:417-423. https://doi.org/10.1002/mawe.19970280907 